\title{
Altimeter data assimilation in the tropical Indian Ocean using water property conserving scheme
}

\author{
Bhasha M Mankad, Rashmi Sharma, Sujit Basu* and P K Pal \\ Atmospheric and Oceanic Sciences Group, Space Applications Centre, Ahmedabad 380 015, India. \\ *Corresponding author. e-mail: rumi_jhim@yahoo.com
}

\begin{abstract}
Altimeter data have been assimilated in an ocean general circulation model using the water property conserving scheme. Two runs of the model have been conducted for the year 2004. In one of the runs, altimeter data have been assimilated sequentially, while in another run, assimilation has been suppressed. Assimilation has been restricted to the tropical Indian Ocean. An assessment of the strength of the scheme has been carried out by comparing the sea surface temperature (SST), simulated in the two runs, with in situ derived as well as remotely sensed observations of the same quantity. It has been found that the assimilation exhibits a significant positive impact on the simulation of SST. The subsurface effect of the assimilation could be judged by comparing the model simulated depth of the $20^{\circ} \mathrm{C}$ isotherm (hereafter referred to as D20), as a proxy of the thermocline depth, with the same quantity estimated from ARGO observations. In this case also, the impact is noteworthy. Effect on the dynamics has been judged by comparison of simulated surface current with observed current at a moored buoy location, and finally the impact on model sea level forecast in a free run after assimilation has been quantified in a representative example.
\end{abstract}

\section{Introduction}

Data assimilation is the process of combining a physical model with observational data to provide a state analysis of the system which is better than could be obtained using just the data or physical model alone (Anderson et al 1996). In relation to ocean circulation modelling, arguably the most important parameter, the assimilation of which has been studied quite thoroughly, is the sea level, derived by satellite altimeters (hereafter simply referred to as altimeter data). Over the years, many techniques have been developed to assimilate altimeter data in ocean circulation models. Most critical need in such assimilations is to find a suitable method to project this surface restricted dataset downwards to infer subsurface information required by the multilevel primitive equation models. In the initial years, statistical correlations were used (De Mey and Robinson 1987; Hurlburt et al 1990; Ezer and Mellor 1994) to accomplish this task. A second approach used in the early years was to assimilate surface observations only at the surface and rely on model dynamics to reproduce associated subsurface features. Thus, Hurlburt (1986) and Berry and Marshall (1989) attempted to do this by inserting surface pressure, while Holland and Malanote-Rizzoli (1989), Verron (1992) and Haines et al (1993) introduced nudging in surface velocities. Because of its computational simplicity, the nudging technique has been used even in later years for assimilating altimeter data in the multilayer circulation model (Basu et al 2003).

Keywords. Data assimilation; altimeter data; ocean general circulation model; thermocline depth; sea surface temperature; modeling; oceanography; remote sensing. 
More sophisticated and advanced techniques have been used in recent years for assimilating altimeter data into ocean circulation models. Thus, Verron et al (1999) used extended Kalman filter to assimilate altimeter data into a numerical model of the tropical Pacific. The ensemble Kalman filter (Evensen and van Leeuwen 1996) has also gained wide acceptance among oceanographers involved in data assimilation. We just mention the representative study by Oke et al (2005). Other known techniques are mode decomposition (Fukumori et al 1999), variational method (Weaver et al 2003) and multivariate covariance method(Borovikov et al 2005).

These sophisticated and advanced techniques are, however, computationally demanding and simpler schemes are still widely used while assimilating altimeter data into primitive equation models. Thus, in a recent study Lin et al (2007) demonstrated the power of the correlation technique of Ezer and Mellor (1994). More recently this correlation technique has been successfully used by Ratheesh et al (2012) for assimilating satellite altimeter data in an Indian Ocean version of the Princeton Ocean Model. Earlier, Fox et al (2000) successfully used the water property conserving scheme of Cooper and Haines (1996) to assimilate altimeter data in a global primitive equation multilevel model. Kantha et al (2008) have carried out a data assimilative hindcast to analyse the Indian Ocean circulation and its variability. The technique used is the earlier mentioned empirical orthogonal function (EOF) technique of Lopez and Kantha (2000) for vertical projection of altimeter data. Thus, it seems that the simpler techniques are still appealing, particularly when computerintensive primitive equation models are concerned, and when such data-assimilative models are to be used in operational scenario by users with limited computational resources.

In the present study, Cooper and Haines (1996) scheme has been used to assimilate sea level anomaly (SLA), obtained as a merged product consisting of data from several altimeters, into an ocean general circulation model (OGCM). This model had been earlier transferred to the Indian Navy for carrying out hindcast and forecast in an operational scenario. It is thus interesting to see if this assimilation scheme is useful in providing good quality analysed ocean status to the navy. A spin-off could be also the improved forecast capability. The reason for choosing the Cooper and Haines (1996) scheme is obviously because of its simplicity and also because its effectiveness has been demonstrated by Fox et al (2000), using a similar kind of primitive equation model. Although, there are more sophisticated methods such as ensemble Kalman filter, and 4-D varia- tional technique, these require huge computing resources. Thus, the ensemble Kalman filter technique requires inversion of matrices of very large order, while $4-\mathrm{D}$ variational technique requires multiple forward runs of the forward model and backward runs of the adjoined model. Hence, simpler techniques are still preferred in operational scenario. This was the major motivation of the present study. However, the assimilation has been restricted to the tropical Indian Ocean (TIO). Impact of assimilation has been quantified in terms

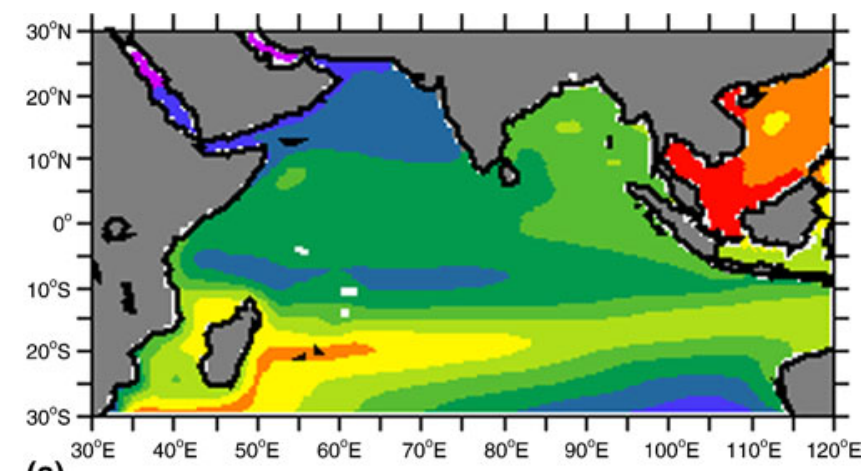

(a)

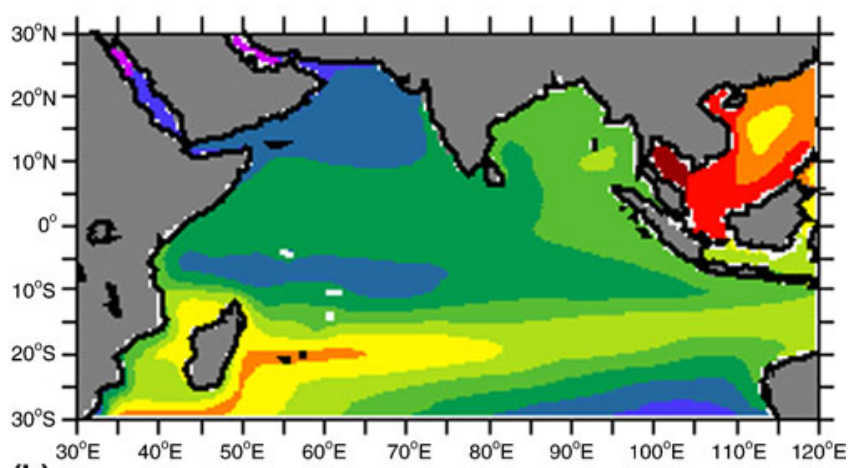

(b)

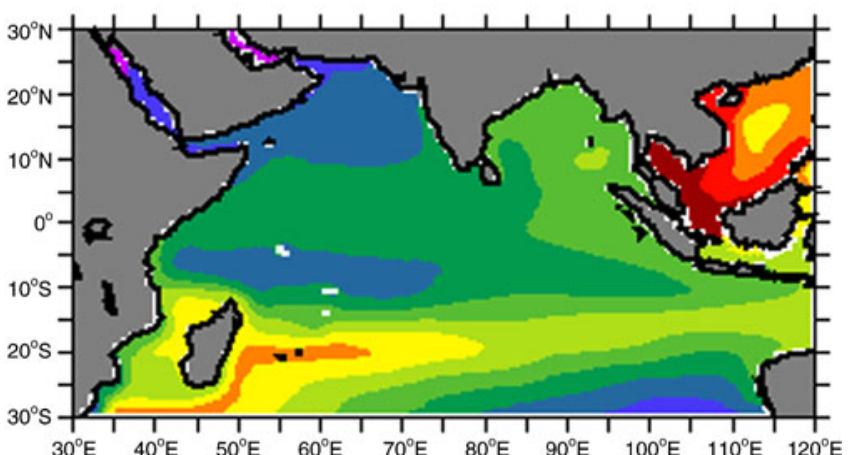
(c)

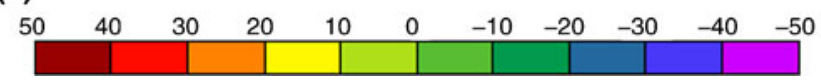

Figure 1. The mean sea surface height (in $\mathrm{cm}$ ) simulated by the model. (a) Average of 1993-1999; (b) average of 19931999 and 2004 control run; and (c) average of 1993-1999 and 2004 assimilation run. 
of sea surface temperature, thermocline depth and surface current at a moored buoy location. Improvement in forecast capability has also been studied.

\section{Model and data}

The OGCM used in this study is the Modular Ocean Model version 3.0 (MOM3) from GFDL, Princeton University (Pacanowski and Griffies 2000). For the present study, the model horizontal resolution has been set to nested grid with finer resolution of $0.5^{\circ} \times 0.5^{\circ}$ in the TIO and $2^{\circ} \times 2^{\circ}$ in the rest of the domain. The model domain is $180^{\circ} \mathrm{W}-180^{\circ} \mathrm{E}$ and $80^{\circ} \mathrm{S}-80^{\circ} \mathrm{N}$. The cut-off in the north and south is to avoid the effect of ice-sheets. At the north and south boundaries, sponge boundary condition has been used in which a Newtonian damping term is added to the tracer equation that damps the solution back to data within a specified width from the walls. There are 38 levels in the vertical with 20 levels in the upper $150 \mathrm{~m}$. The bottom topography is based on $1 / 12^{\circ}$ by $1 / 12^{\circ}$ resolution data from the US National Geophysical Data Centre. A wind-dependent drag coefficient (Large and Pond 1982) is used in the model for converting wind to wind stress using bulk aerodynamic formula. The model is spun up from the rest for 50 years using climatological winds and restoring boundary conditions for sea surface temperature (SST) and sea surface salinity (SSS). The initial thermodynamic state consists of climatological temperature and salinity values at each model level. The SST and SSS are relaxed to climatological values using suitable damping coefficients. Further, the model is integrated with daily winds, near-surface air temperature, specific humidity, net solar radiation and net long wave radiation, precipitation rate, etc., from 1999 until the end of 2003. All the parameters are taken from NCEP reanalysis. Latent and sensible heat fluxes are calculated using bulk aerodynamic formulae and the same wind-dependent drag coefficient is used for wind-stress computation. Monthly climatological river discharge data for 3000 rivers were downloaded from the United Nations Educational, Scientific and Cultural Organization (UNESCO) site for use in the model. The river discharge is distributed as volume transport, and it is distributed over 2-3 grid points around the river mouths of major rivers. These data are monthly averaged river discharge estimates from Vorosmarty et al (1998).

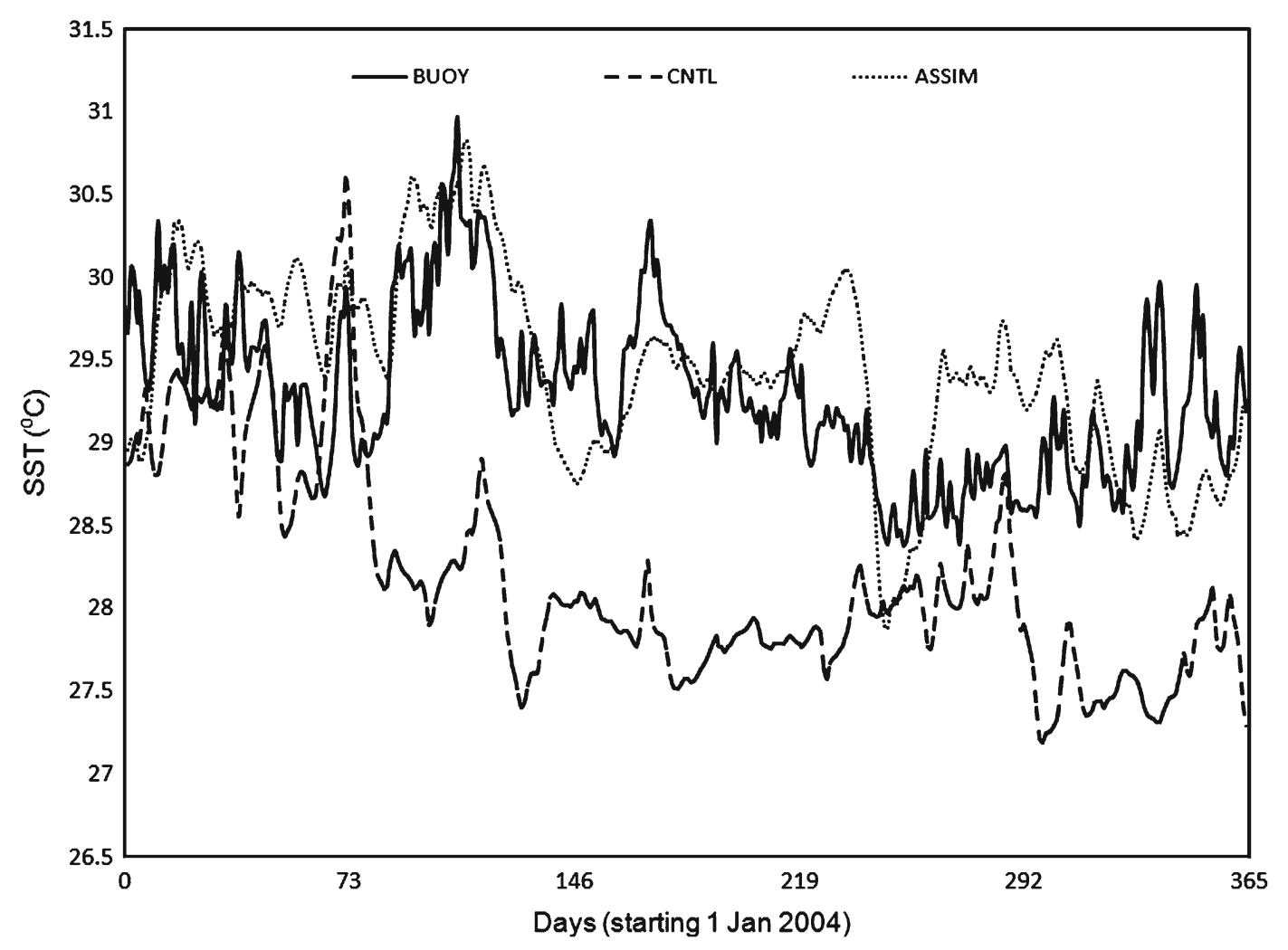

Figure 2. Time series of SST observed by RAMA buoy and simulated by the model in control and assimilation runs. The location of the buoy is shown in figures 3 and 4 . 
It has been demonstrated earlier (Agarwal et al 2007) that the model used in this study provides much better simulation of sea level, surface current and D20, when forced by QuikSCAT scatterometer winds than when forced by NCEP winds. Accordingly, in the experimental run for the year 2004, analysed QuikSCAT scatterometer winds obtained from ftp://ftp.ifremer.fr have been used as the dynamic forcing for the model.

The MSLA data used in this study have been obtained from the AVISO website as a weekly average at every $0.25^{\circ}$ interval for the year 2004. The data have been further averaged to $0.5^{\circ}$ resolution in conformity with the model resolution. For validating the model simulated SST, the SST available from RAMA buoy located at $90^{\circ} \mathrm{E}, 1.5^{\circ} \mathrm{S}$ has been used. A continuous time series of SST for the whole of 2004 is available only for this buoy. RAMA is an acronym for Research Moored Array for AfricanAsian-Australian Monsoon Analysis and Prediction. The surface currents observed by this buoy have also been used for validating the results of assimilation. As in SST, continuous time series of currents is available only for this buoy. Apart from the buoy data, daily averaged satellite-derived SST has also been used in the present study. This dataset is a blended product of the SSTs measured by advanced very high resolution radiometer (AVHRR) and advanced microwave scanning radiometer (AMSR). It has been shown (Reynolds et al 2007) that the combined product AVHRRAMSR obtained through optimal interpolation (OI) has improved the spatial and temporal resolution compared to earlier $1^{\circ}$ weekly OI analyses. In the present study, the product available at a spatial resolution of $0.25^{\circ}$ has been averaged to a spatial resolution of $0.5^{\circ}$. Apart from SST, subsurface temperature profiles obtained from ARGO floats in the Indian Ocean have also been used. It is a gridded product obtained from original ARGO profiles during the year 2004. The data have been kindly provided by the Indian National Centre for Ocean Information Services (INCOIS). The gridding is done by objective analysis, the details of which are available in Udaya Bhaskar et al (2007).

\section{Assimilation scheme used}

Updates to the sea surface height field simulated by the model are projected to the subsurface using a simple lifting/lowering scheme (Cooper and Haines 1996; Fox et al 2000). The entire column is displaced vertically and the water parcels moving upwards or downwards carry their properties such as temperature and salinity along with them.
Mathematically, the scheme can be represented by the following equation:

$$
\Delta p(z)=\Delta p_{s}+g \int_{z}^{0} \Delta \rho(z) \mathrm{d} z,
$$

where $\Delta \rho(z)$ are the subsurface density changes, occurring as a result of lowering/lifting of water column. The equation simply expresses the hydrostatic connection between change in surface

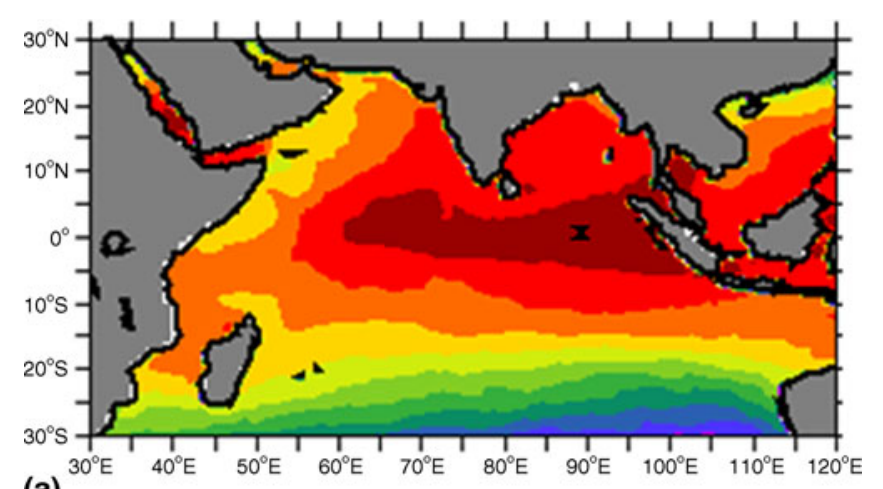

(a)

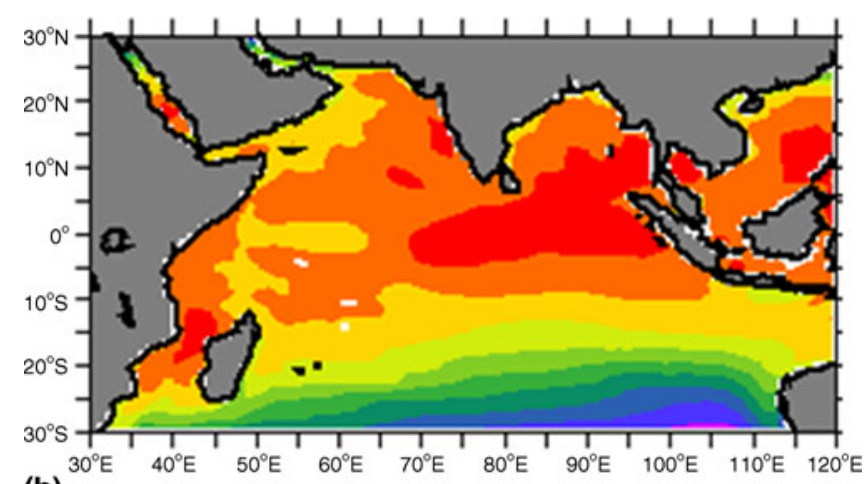

(b)
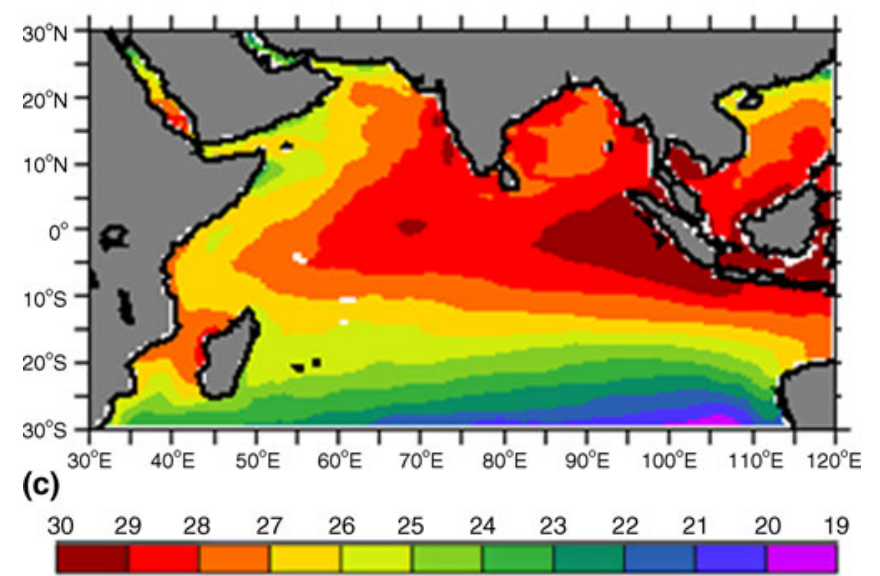

Figure 3. Spatial distribution of mean $\mathrm{SST}$ in ${ }^{\circ} \mathrm{C}$ : (a) satellite-derived, (b) simulated in the control run, and (c) simulated in the assimilation run. The cross in (a) denotes the RAMA buoy location. 
pressure $\Delta p_{s}$ and subsurface pressure updates $\Delta p(z)$.

At the ocean bottom $(z=-H)$ equation (1) reads

$$
\Delta p_{b}=\rho_{0} g \Delta \eta+g \int_{-H}^{0} \Delta \rho(z) \mathrm{d} z
$$

where $\rho_{0}$ is surface density and $\Delta p_{b}$ is the change in bottom pressure. Moreover, $\Delta p_{s}$ has been replaced by the product of $\rho_{0} g$ and $\Delta \eta$, which is the difference in sea levels observed by altimeter and simulated by the model.

One has to infer the subsurface density increments from this equation in which the only known quantity is $\Delta \eta$. Since, $\Delta p_{b}$ is also unknown, this is an open problem and has no solution. To close the problem, one makes the plausible assumption that $\Delta p_{b}=0$. This ensures that the bottom pressure and current distribution (through geostrophy, wherever applicable) are not altered. It is a good choice practically everywhere, except, e.g., on continental shelves or in regions of strong barotropic flow (Cooper and Haines 1996). This is equivalent to assuming a level of no-motion-change. Finally we come to the integral equation

$$
g \int_{0}^{-H} \Delta \rho(z) \mathrm{d} z=\rho_{0} g \Delta \eta .
$$

It is impossible to solve even this equation without any auxiliary information. The lifting/lowering of water column now comes into force. The entire column is lifted (or, lowered, depending on the

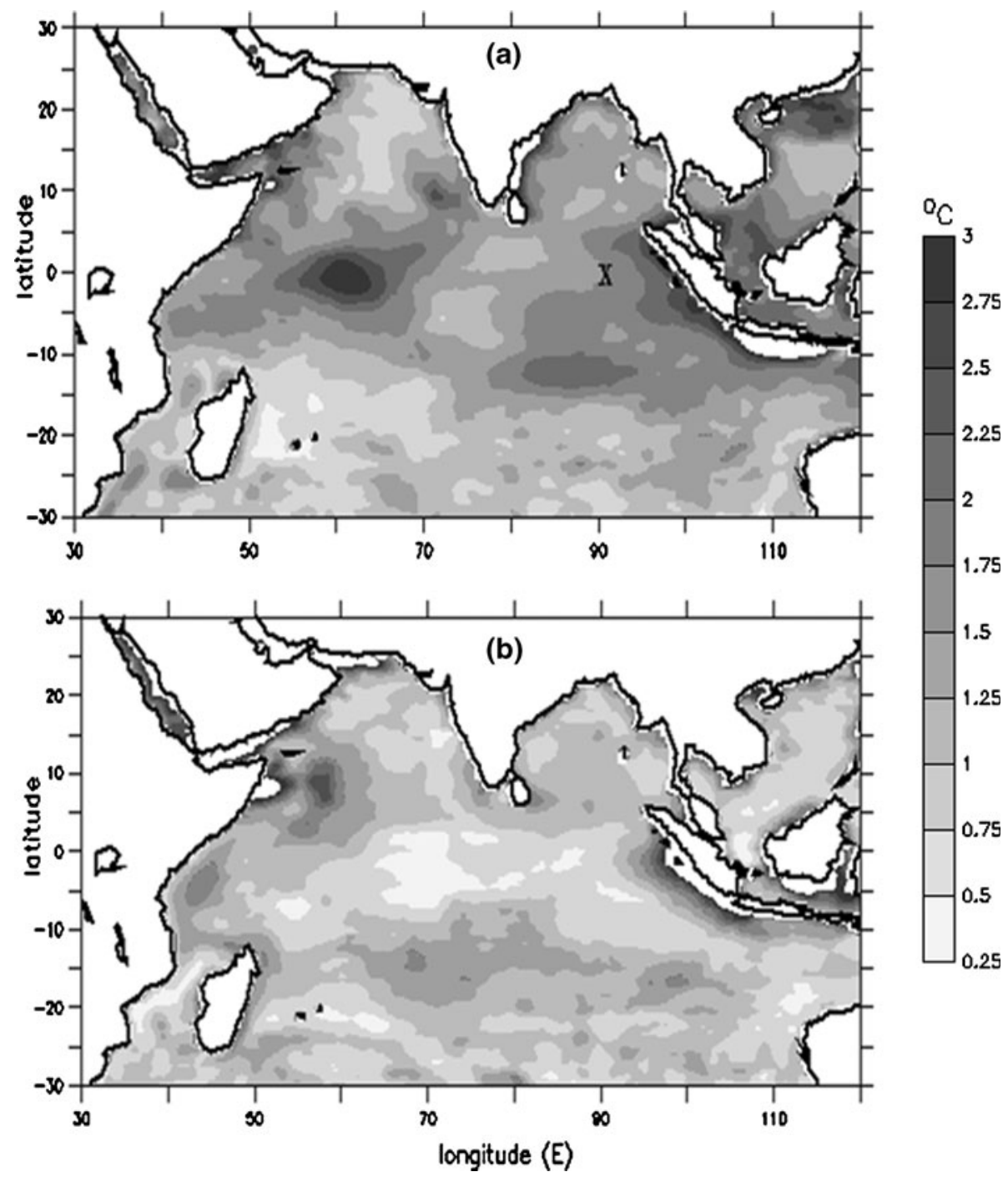

Figure 4. Spatial distribution of RMSE of simulated SST in ${ }^{\circ} \mathrm{C}$ : (a) control run and (b) assimilation run. The cross in (a) denotes the RAMA buoy location. 
sign of $\Delta \eta$ ) by a certain amount $\Delta h$, the vertical displacement of the column. Thus, the change in the entire temperature and salinity profile (with the resulting change in density profile), is governed by the single parameter $\Delta h$. Physically speaking, if the sea level is to be lowered (to agree with altimeter sea level), the model water columns are displaced upwards and light surface waters are lost and replaced by some denser bottom waters. Thus, in the case of sea level lowering, the loss in the weight of a few centimetres of water column depth is compensated by increasing the weight of the remaining water by lifting by some metres. The converse happens if the sea level is to be raised. In this case, the thermocline is lowered so that relatively lighter water comes to the bottom to compensate for the gain in weight at the surface. A cubic spline approach followed by an iterative procedure is used to determine $\Delta h$. The procedure is outlined in the Appendix of Cooper and Haines (1996).

\section{Results}

Two runs of the model have been performed during 2004. In the reference run designated as control run (CNTL-R), the model is forced with daily fluxes from NCEP reanalysis and analysed winds from QuikSCAT scatterometer. In this run, no assimilation has been conducted. In the assimilation run (ASSIM-R), weekly MSLA data are assimilated sequentially in the model, while forcings remain the same as for CNTL-R. Since a satellite altimeter provides only sea level anomaly, a mean sea surface height (MSSH) is needed to be added to this anomaly for obtaining sea level. Following standard practice, a model-derived MSSH has been added. This MSSH is an average over 1993-1999, to correspond with the MSSH used for calculating the altimeter-derived MSLA. The assimilation was effected through the water property conserving scheme (Fox et al 2000). To demonstrate the fact that the assimilation scheme is stable as far as MSSH is concerned, we show this MSSH calculated in three different ways in figure 1 . In the top panel, the mean is an average for the period 1993-1999 and is the one which was actually used in assimilation. In the middle and bottom panels, the simulated SSH for the year 2004 was added to the SSH for the other years while computing the MSSH. This was done separately for the control and assimilation runs. It can be clearly seen that the three means are practically indistinguishable demonstrating the stability of the scheme with respect to MSSH. The simulated SSTs in both the runs at $90^{\circ} \mathrm{E}, 1.5^{\circ} \mathrm{S}$ have been compared with RAMA buoy SST, and the result of the comparison is shown in figure 2. It is clear from the figure that the assimilation has been able to significantly enhance the quality of simulation, although the degree of improvement is not uniformly spread over the months. Altimeter data assimilation is primarily aimed towards correction of subsurface

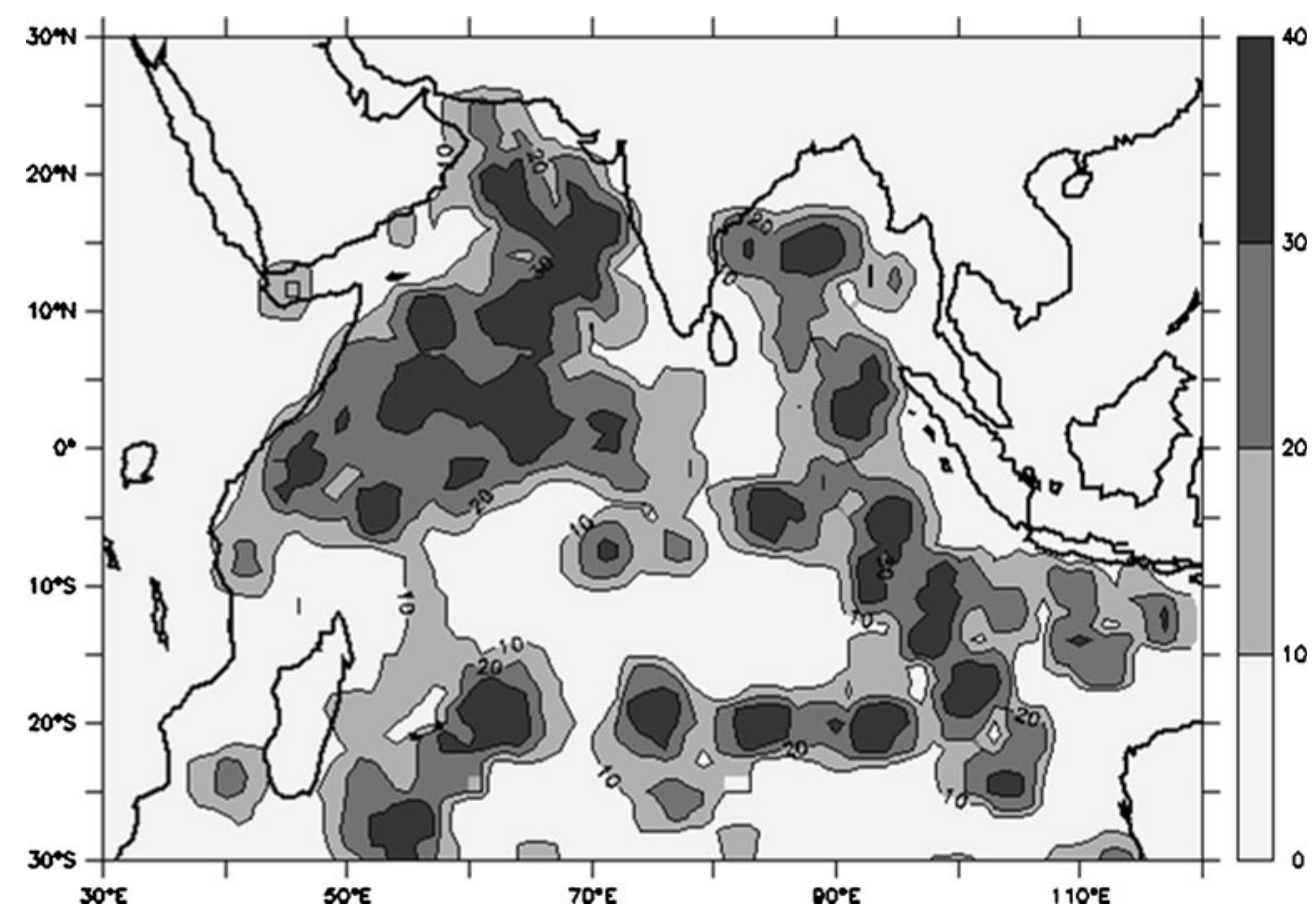

Figure 5. Distribution of ARGO profiles during 2004 in the area of study. 
$\mathrm{T} / \mathrm{S}$ profiles via the lifting/lowering scheme. The correction of other parameters such as the SST and the sea surface current is somewhat indirect, effected via model dynamics and thermodynamics. Drastic improvement in SST simulation evidently requires SST assimilation, which will be taken up in future. However, the overall cold bias of the model, occurring primarily due to the inaccuracy of the heat fluxes and also due to the imbalance between the QuikSCAT scatterometer wind forcing and NCEP heat fluxes, has been removed to a large extent. Because of this bias correction, the overall root mean square error (RMSE) has also decreased from $1.32^{\circ}-$ $0.52^{\circ} \mathrm{C}$.

Because of the sparse availability of in situ data, spatially distributed satellite data provides a better alternative for basin wide comparison. In figure 3,
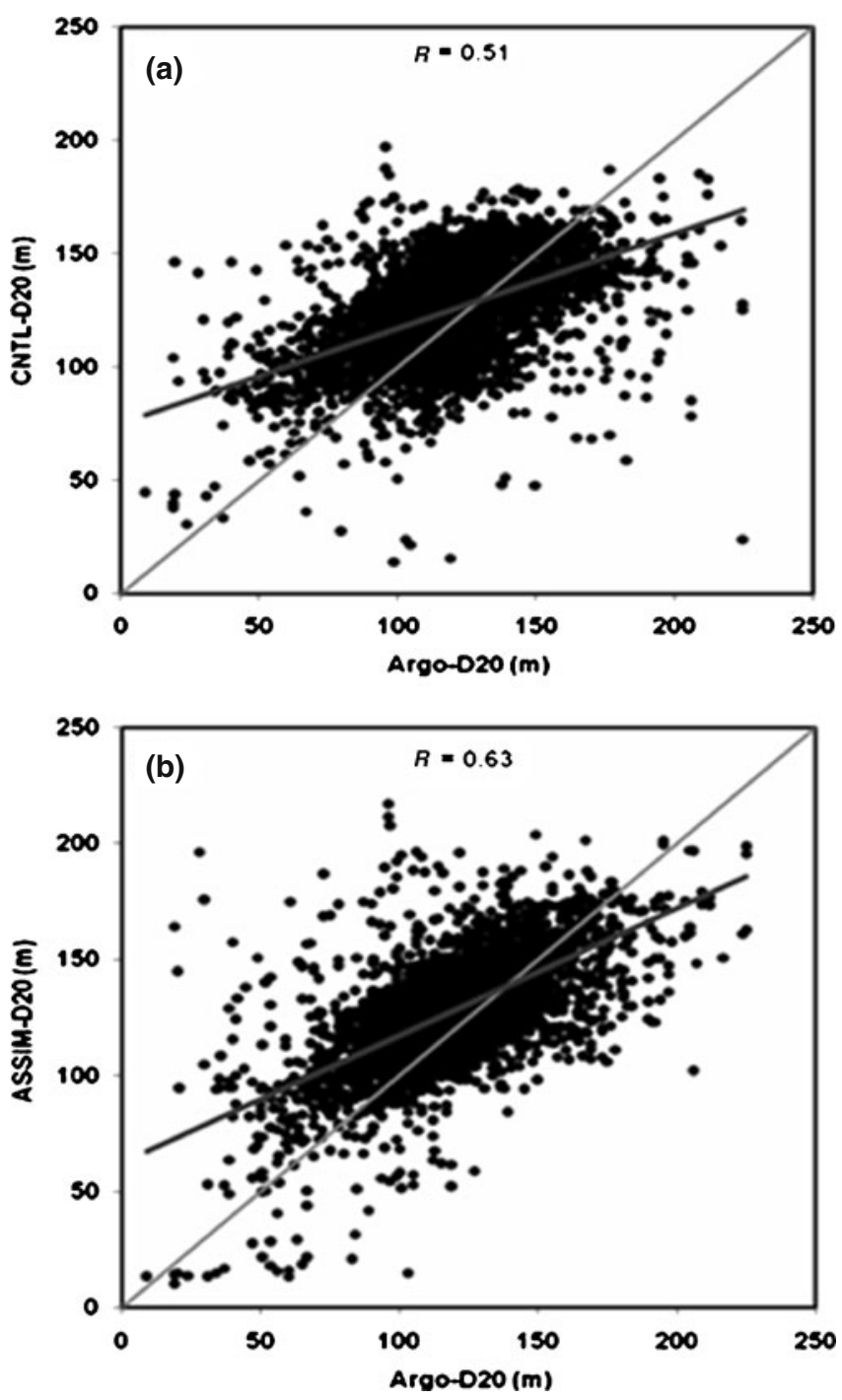

Figure 6. Scatter plots (a) between CNTL-D20 and ArgoD20, and (b) between ASSIM-D20 and Argo-D20.

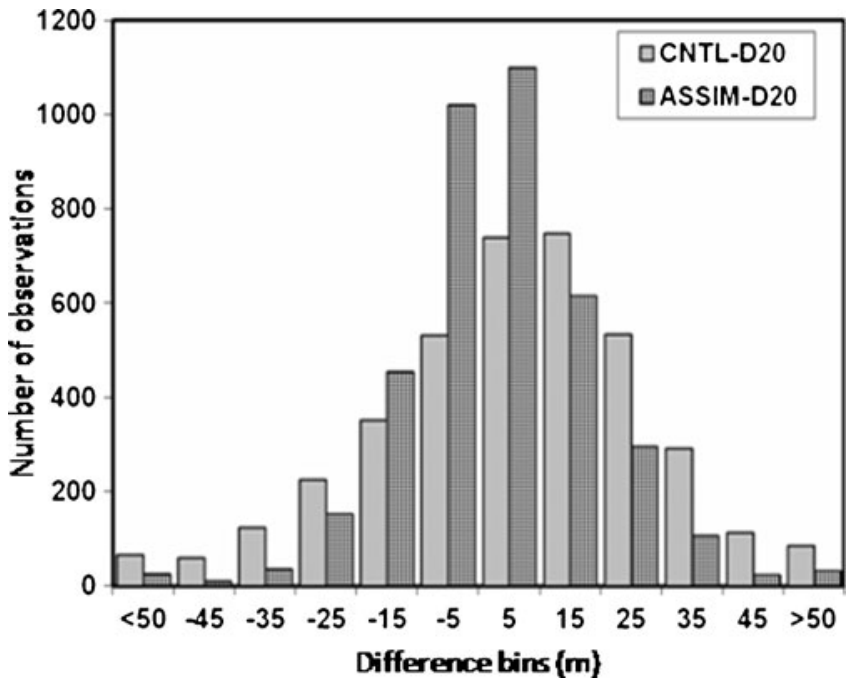

Figure 7. Frequency distribution chart of differences between Argo-D20 and simulated D20.

we show the mean SST simulated in the control run as well as in the assimilation run and compare this simulated SST with satellite-derived SST. Again, it is seen that this cold bias has been largely removed because of data assimilation.

Further assessment of the impact of assimilation has been carried out in terms of RMSE. We have computed the RMSE of SST at every grid point of the model in the two runs by taking the satellite-derived SST as truth. The spatial distribution of this RMSE is shown in figure 4. Reduction of RMSE is seen practically everywhere in the case of ASSIM-R, although the improvement is spatially nonuniform.

D20 derived from ARGO data (Argo-D20) has been compared with D20 from the model (CNTLD20 in the case of reference run and ASSIM-D20 for the assimilated run). ARGO profiles nearest to a particular model grid point have been taken to be coincident with that point for the purpose of comparison. In figure 5, we show the distribution of ARGO profiles.

The scatter plots of D20 obtained from ARGO and from the model have been depicted in figure 6 (a, b). The assimilation is able to increase the correlation from 0.51 to 0.63 . The best fit line is closer to $45^{\circ}$ line in the case of ASSIM-D20, indicating a marked improvement from CNTL-D20. In quantitative terms, the slope of the best fit line has increased from 0.42 to 0.55 . It is found that the RMSE has been reduced from $20.61 \mathrm{~m}$ for CNTLD20 to $17.97 \mathrm{~m}$ in case of ASSIM-D20, which is an improvement of the order of $13 \%$. A more definitive judgment on the assimilation skill can be pronounced by looking at figure 7 , which is a frequency histogram of the difference between Argo-D20 and 
simulated D20 spread into various bins. The bins are of $10-\mathrm{m}$ width. It can be seen that there is a significant increase in the number of cases with absolute difference less than $15 \mathrm{~m}$ as a result of assimilation. The width of the distribution has reduced while the height of the central peak has increased, thereby indicating a strong positive impact of the assimilation scheme.

We are quite clear that the simple algorithm used in this study cannot be a replacement for the more elaborate schemes used in operational frameworks such as global ocean data assimilation system (GODAS) with much more computing power and with assimilation of altimetry as well as other auxiliary data. However, the simplicity of this algorithm is an advantage for transferring this data-assimilative model to operational agencies such as the Indian Navy. From this point of view, it is instructive to compare the D20s obtained from this data-assimilative model with the D20s obtained, e.g., from GODAS. In figure 8, we show this as a spatial distribution of RMSE assuming GODAS to be the truth. Since the GODAS values were monthly averaged, we also averaged the D20s obtained from our data-assimilative model on a monthly basis. It can be seen from this figure that the error is less than $18 \mathrm{~m}$ practically everywhere and in a large part of the area of study it is of the order of $12 \mathrm{~m}$. Thus, our simple scheme performs reasonably well, considering the fact that D20 is more than $80 \mathrm{~m}$ in most of the months and gets more than $100 \mathrm{~m}$ in many regions of the area of study during the peaks of summer and winter monsoons.

Another interesting parameter obtained from a numerical circulation model is the surface current. One can judge how the ocean dynamics is affected by assimilation by making a comparison of the currents simulated in the two runs with the currents observed by a RAMA buoy. It is the same buoy from which SST time series was used for validating the assimilation results. The comparison is shown in figure 9 for the zonal and the meridional components. There is considerable improvement in an overall sense as can be judged from the improved RMSEs. Thus, for the zonal component, the RMSE improved from 34.6-23.6 $\mathrm{cms}^{-1}$, while for the meridional component, the corresponding improvement is from $25.4-16.2 \mathrm{~cm} \mathrm{~s}^{-1}$.

A more stringent test of assimilation is to see whether it has been able to improve the forecast capability of a model. After all, this is an

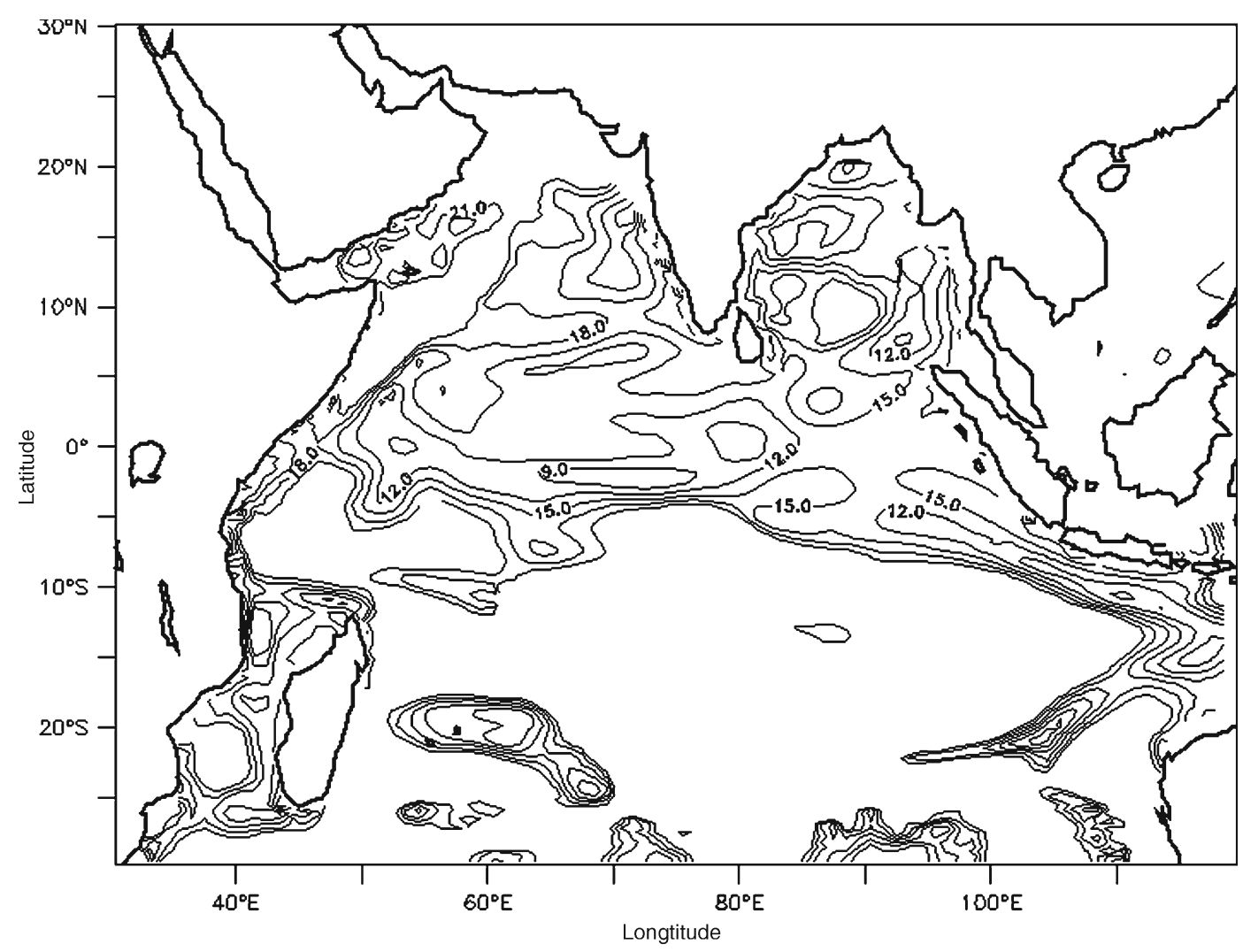

Figure 8. The distribution of RMSE of the monthly averaged D20s with respect to the GODAS monthly averaged D20s. The unit is $\mathrm{m}$. 
important goal of any assimilation study. Accordingly, we have followed Fox et al (2000) and have evaluated the forecast skill in terms of sea level anomaly. Accordingly, in figure 10, we provide a set of snapshots pertaining to 19 April 2004. This date was arbitrarily chosen. The snapshot in figure 10(a) is SLA simulated in the control run, while the snapshot in figure 10(b) is the best analysed SLA, obtained as a result of assimilation up to, and including this date. The SLA snapshot in figure $10(\mathrm{c})$ is a 7-day model forecast on 19 April 2004, carried out in ASSIM-R. However, in these 7 days, no further assimilation was carried out. A 14-day forecast was also conducted. However, the 7-day and 14-day forecasts are virtually indistinguishable. Hence, the corresponding figure is not displayed. These are, of course, not true forecasts, since analysed scatterometer wind fields have been
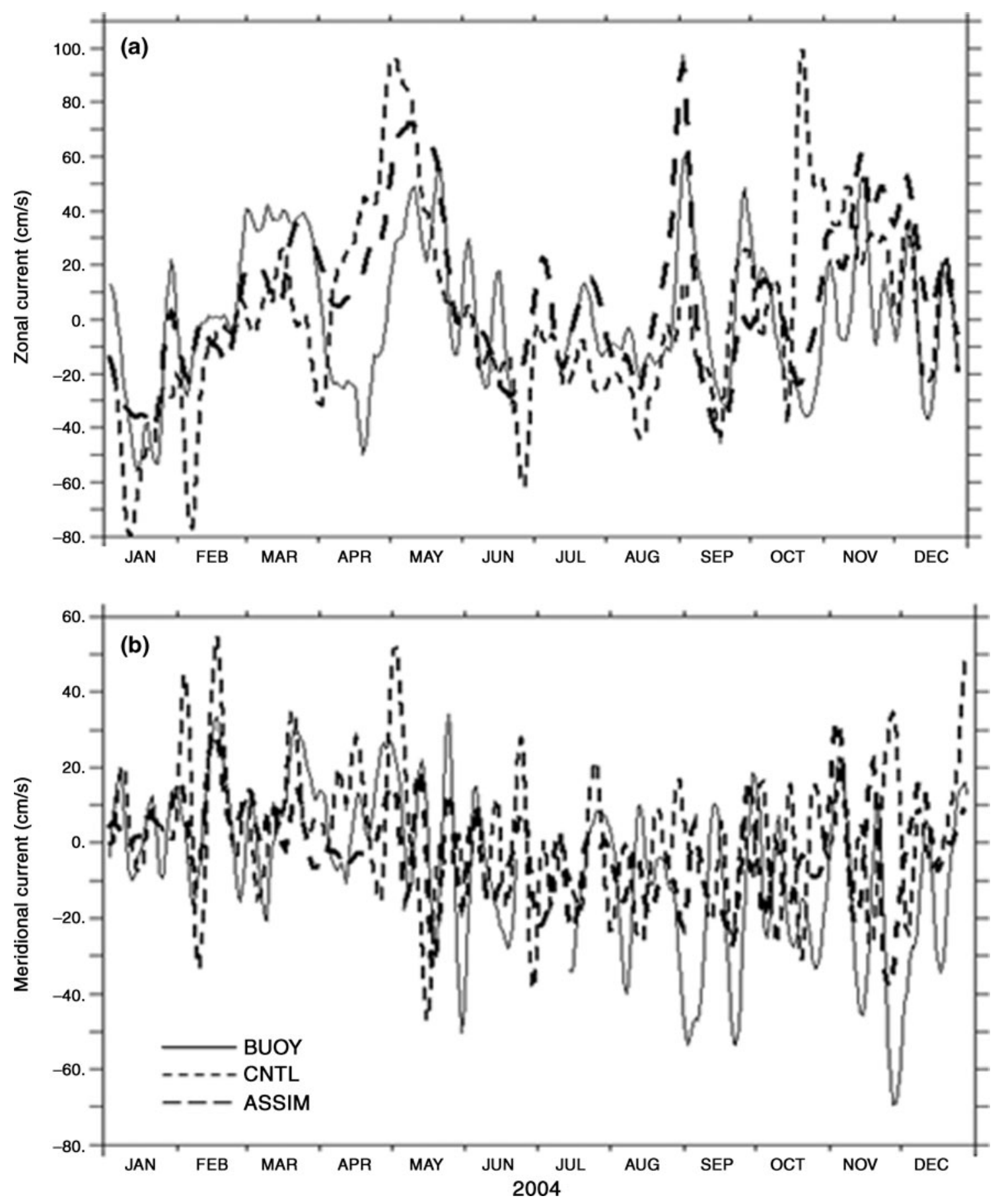

Figure 9. Time series of currents observed by RAMA buoy and simulated in reference and assimilation runs: (a) zonal current and (b) meridional current. The location of the buoy is shown in figures 3 and 4 . 
used as forcing and for true forecasts, we need forecasts from numerical weather prediction (NWP) centres. Nevertheless, in this way, the errors of NWP models will not contribute to the overall forecast errors and one would be able to isolate the
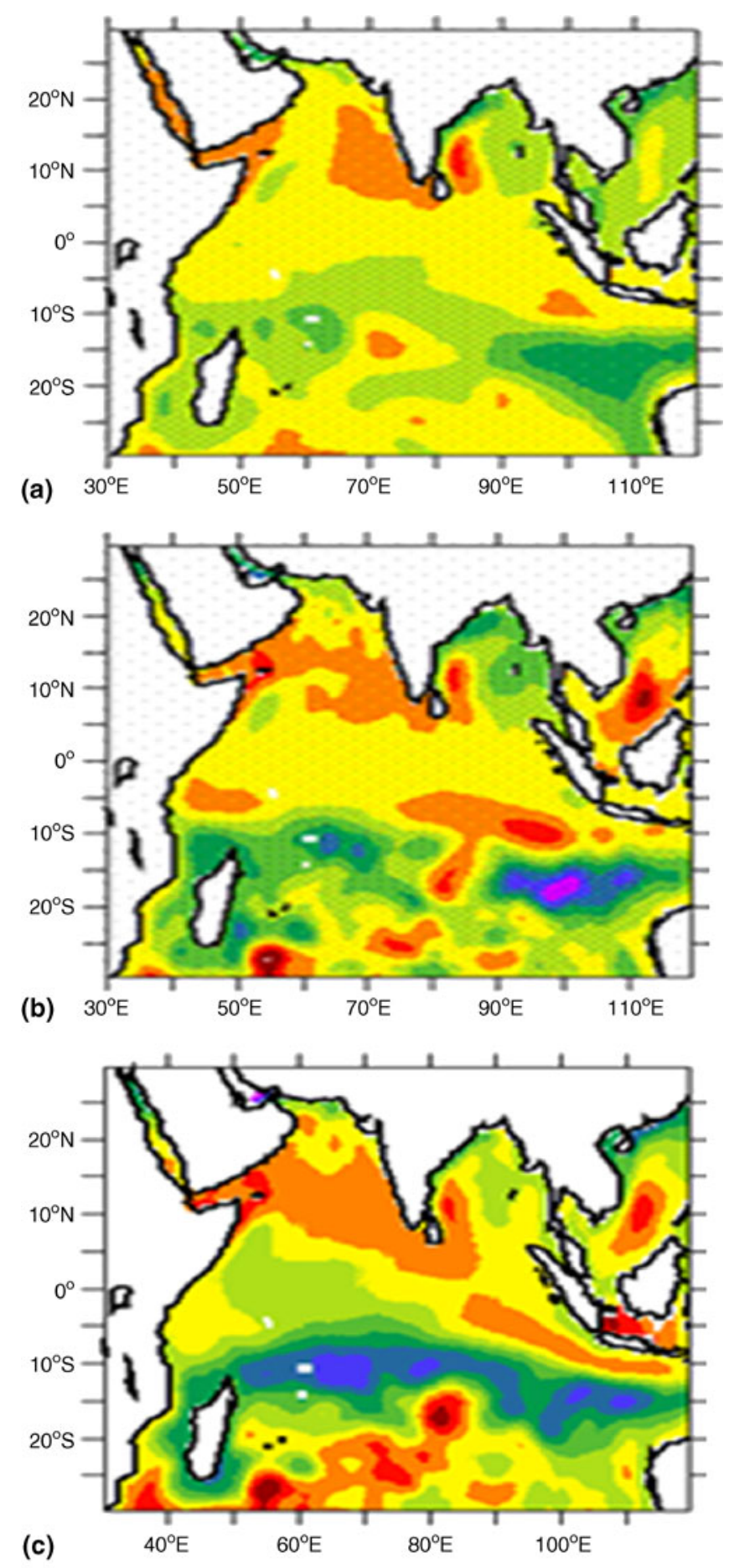

$\begin{array}{lllllllllll}20 & 15 & 10 & 5 & 0 & -5 & -10 & -15 & -20 & -25 & -30\end{array}$

Figure 10. Model forecasts of sea level anomaly (in $\mathrm{cm}$ ) in the Indian Ocean for 19 April 2004: (a) control run, (b) best analysis, and (c) 7-day model forecast. error due to the assimilation scheme. Although, there is no one-to-one correspondence between the best analysis and the 7-day forecast, the impact is quite high in certain pockets of the Indian Ocean, e.g., in the western Arabian Sea, region south of $10^{\circ} \mathrm{S}$, etc.

An interesting eddy-like feature, which was conspicuous by its absence in the region centred on $8^{\circ} \mathrm{N}, 110^{\circ} \mathrm{E}$, has appeared in the 7 -day forecast almost at the same location. The low in the southeastern Indian Ocean, which was absent in the CNTL-R, is present in the 7-day forecast. Thus, it can be said that there is a marked overall improvement in the quality of SLA forecast as a result of assimilation.

\section{Conclusions}

In the present work, merged sea level anomaly obtained from several satellite altimeters has been assimilated in an OGCM using the well-known scheme of water property conservation. Although, there are more advanced schemes of assimilation, simpler schemes are often found to be more suitable in an operational scenario, since they are computationally not too demanding. Keeping such a goal in mind, the scheme has been assessed in terms of its capacity to improve the quality of the simulated SST. The simulated SST without and with assimilation has been compared with SST at an isolated buoy location with continuous data record and it has been found that the assimilation exhibits positive impact. The day-to-day improvement is not very high, because the primary aim of altimeter data assimilation is the correction of subsurface profiles through the lifting/lowering scheme. The correction of other variables such as SST and surface current is somewhat indirect, effected primarily via model dynamics and thermodynamics. Nevertheless, there is a significant impact of data assimilation. We are referring to the cold bias in SST known to occur in this model (Agarwal et al 2007) primarily because of the inaccuracy of the surface heat fluxes in NCEP reanalysis and also because of the imbalance between QuikSCAT scatterometer winds and NCEP fluxes used to force the model. This cold bias has been reduced to a large extent by the data assimilation.

This reduction in cold bias is not an isolated effect, restricted to the buoy location only. The comparison of spatially distributed SST simulated in the control and assimilation runs with satellitederived SST is a testimony to this fact. The positive impact of assimilation has been confirmed by a reduction not only of the cold bias, but also of the RMSE. It is also interesting to see how the assimilation of sea level data influences the subsurface 
parameters, since sea level (in particular, its steric part) is known to be an integrated effect of the subsurface temperature and salinity distribution. Accordingly, the depths of the $20^{\circ} \mathrm{C}$ isotherm (as a proxy of the thermocline depth) in both the runs have been compared with the same quantity estimated from ARGO profiles. It has been found that there is a strong impact of assimilation in this case also.

Since the steric part of the sea level is considerably influenced by temperature profiles, it is not surprising that altimeter data assimilation has produced positive impact on simulations of sea surface temperature and thermocline depth. We have, however, refrained from assessing the impact of assimilation on the salinity structure simulated by the model. This is because such types of coarse resolution models (with $0.5^{\circ}$ horizontal resolution) are not suitable for a faithful simulation of the salinity structure in the Indian Ocean and most notably so, in the Bay of Bengal (Durand et al 2011). Intrusion of Bay of Bengal low salinity waters in the equatorial Indian Ocean and in the Arabian Sea inferred from previous observational studies (Shetye 1993; Shankar and Shetye 1999) as well as from numerical studies (Han and McCreary 2001; Durand et al 2007) are not well-reflected in the model simulations, and altimeter data assimilation in isolation would not be able to correct this deficiency. Possibly assimilation of sea surface salinity, to be available from Soil Moisture and Ocean Salinity Mission (SMOS), would be able to correct this deficiency to a certain extent. However, there are other limitations of the model. The intraseasonal variability of the East India Coastal Current (EICC) observed in the altimetric data by Durand et al (2009) is significantly underestimated by such models (Durand et al 2011). Other drawbacks are the overestimation of the width of EICC and incorrect representation of turbulence. These drawbacks would lead to an incorrect simulation of all the coastal currents.

Having said this, it is nevertheless interesting to investigate how this coarse-resolution model responds to the altimetric assimilation in terms of deep ocean currents. Unfortunately, we were constrained by the presence of only an isolated RAMA buoy in our area of study during 2004. This buoy provided continuous surface current observations. It was found that in this case also, there is reduction in RMSE for both the components.

Since one of the goals of any assimilation is an enhancement of the forecast capability, it was interesting to see whether there was any such enhancement in this case. This was judged by stopping the assimilation at some point of time and by carrying out a 7-day forecast from this point of time. One date was arbitrarily chosen and it was found that there was indeed such an enhancement in the forecast quality.

Summarizing, it can be said that we have demonstrated the efficiency of a relatively simple algorithm for assimilating mapped altimeter data in a coarse resolution OGCM in which assimilation has been restricted to our area of study, which is the Indian Ocean. This seems to work well from the point of view of transferring to an operational agency such as the Indian Navy. Of course, in future this scheme should be further substantiated by assimilation of other data such as SST and subsurface ARGO profiles in an eddy-resolving ocean circulation model with better representation of coastal currents so that data from forthcoming SARAL/AltiKA mission (better suited for coastal altimetric studies) could be assimilated in a more efficient manner in such a model.

\section{Acknowledgements}

The authors would like to thank $\operatorname{Dr} R \quad R$ Navalgund, Director, Space Applications Centre, Dr J S Parihar, Deputy Director, Earth, Ocean, Atmosphere and Planetary Sciences and Applications Area and Dr Rajkumar, Head, Oceanic Sciences Division for their continuous support and encouragement. Sincere thanks are due to Dr. Neeraj Agarwal, Max Planck Institute fur Meteorology, Hamburg, Germany, for numerous helpful discussions. They also thank Geophysical Fluid Dynamics Laboratory for providing the MOM3 code and related datasets. The MSLA data are obtained from www.aviso.com. The QuikSCAT winds and NCEP reanalysis fields are obtained from ftp://ftp.ifremer.fr and ftp://ftp.cdc.noaa.gov respectively. The RAMA buoy data are from http://www.pmel. noaa.gov. AVHRR-AMSR SST data are from ftp://eclipse.ncdc.noaa.gov. Finally, authors would like to express their sincere gratitude to the anonymous reviewers and the Associate Editor for several helpful comments and suggestions.

\section{References}

Agarwal N, Sharma R, Basu S, Sarkar A and Agarwal V K 2007 Evaluation of relative performance of QuikSCAT and NCEP re-analysis winds through simulations by an OGCM; Deep-Sea Res. I 54 1311-1328.

Anderson D L T, Sheinbaun J and Haines K 1996 Data assimilation in ocean models; Rep. Prog. Phys. 59 12091266.

Basu S, Bhatt V, Kumar R and Agarwal V K 2003 Assimilation of satellite altimeter data in a multilayer Indian Ocean circulation model; Indian J. Mar. Sci. 32 181-193. 
Berry P J and Marshall J C 1989 Ocean modeling studies in support of altimetry; Dyn. Atmos. Oceans 13 269-300.

Borovikov A, Rienecker M M, Keppenne C L and Johnson G C 2005 Multivariate error covariance estimates by Monte Carlo simulation for assimilation studies in the Pacific Ocean; Mon. Weather Rev. 133 2310-2334.

Cooper M and Haines K 1996 Altimetric assimilation with water property conservation; J. Geophys. Res. 10 1059-1077.

De Mey P and Robinson A R 1987 Assimilation of altimeter eddy fields in a limited-area quasi-geostrophic model; J. Phys. Oceanogr. 17 2280-2293.

Durand F, Shankar D, de Boyer Montégut C, Shenoi S S C, Blanke B and Madec G 2007 Modeling the barrier-layer formation in the south-eastern Arabian Sea; J. Climate 20 2109-2120, doi: 10.1175/JCLI4112.1.

Durand F, Shankar D, Birol F and Shenoi S S C 2009 Spatio-temporal structure of the East India Coastal Current from satellite altimetry; J. Geophys. Res. 14 C020, doi: 10.1029/2008JC004807.

Durand F, Papa F, Rahman A and Bala S K 2011 Impact of Ganges-Brahmaputra interannual discharge variations on Bay of Bengal salinity and temperature during the 1992-1999 period; J. Earth Syst. Sci. 120(5) 859-887.

Evensen G, van Leeuwen P J 1996 Assimilation of Geosat altimeter data for the Agulhas Current using the ensemble Kalman filter with a quasi-geostrophic model; Mon. Weather Rev. 124 85-96.

Ezer T and Mellor G 1994 Continuous assimilation of GEOSAT altimeter data into a three-dimensional primitive equation Gulf stream model; J. Phys. Oceanogr. 21 843-868.

Fox A D, Haines K, de Cuevas B A and Webb D J 2000 Altimeter assimilation in the OCCAM global model. Part II: TOPEX/POSEIDON and ERS-1 assimilation; J. Mar. Syst. 26 323-347.

Fukumori I, Raghunath R, Fu L L and Chao Y 1999 Assimilation of TOPEX/POSEIDON altimeter data into a global ocean circulation model: How good are the results? J. Geophys. Res. 104 25,647-25,665.

Haines K, Malanotte-Rizzoli P, Young R E and Holland W R 1993 A comparison of two methods for the assimilation of altimeter data into a shallow water model; Dyn. Atmos. Oceans 17 89-133.

Han W and McCreary J P 2001 Modeling salinity distributions in the Indian Ocean; J. Geophys. Res. 106 859-877.

Holland W R and Malanotte-Rizoli P 1989 Assimilation of altimeter data into an ocean model: Space versus time resolution studies; J. Phys. Oceanogr. 19 1507-1534.

Hurlburt H E 1986 Dynamic transfer of simulated altimeter data into subsurface information by a numerical ocean model; J. Geophys. Res. $912372-2400$.

Hurlburt H E, Fox D N and Metzger E J 1990 Statistical inference of weakly correlated subthermocline fields from satellite altimeter data; J. Geophys. Res. 95 11,37511,409 .

Kantha L, Rojsiraphisal T and Lopez J 2008 The North Indian Ocean circulation and its variability as seen in a numerical hindcast of the years 1993-2004; Prog. Oceanogr. 76 111-147.

Large W G and Pond S 1982 Sensible and latent heat flux measurements over the ocean; J. Phys. Oceanogr. 12 464-482.

Lin X H, Oey L H and Wang D P 2007 Altimetry and drifter data assimilations of loop current and eddies; J. Geophys. Res. 112, doi: 10.1029/2006JC003779.

Lopez J W and Kantha L H 2000 A data-assimilative numerical model of the northern Indian Ocean; J. Atmos. Ocean. Tech. 17 1525-1540.

Oke P R, Schiller A, Griffin D A and Brassington G B 2005 Ensemble data assimilation for an eddy-resolving ocean model; Q. J. R. Meteorol. Soc. 131 3301-3311.

Pacanowski R and Griffies S M 2000 MOM3.0 Manual; NOAA/Geophysical Fluid Dynamics Laboratory, Report, $680 \mathrm{p}$.

Ratheesh S, Sharma R and Basu S 2012 Projection based assimilation of satellite derived surface data in an Indian Ocean circulation model; Marine Geodesy (in press).

Reynolds R W, Smith T M, Liu C, Chelton D B, Casey K S and Schlax M G 2007 Daily high-resolution-blended analyses for sea surface temperature; J. Climate 20 5473-5496.

Shankar D and Shetye S R 1999 Are interdecadal sea level changes along the Indian coast influenced by variability of monsoon rainfall? J. Geophys. Res. 104(C11) 26,03126,042 .

Shetye S R 1993 The movement and implications of the Ganges-Bramhaputra runoff on entering the Bay of Bengal; Curr. Sci. 64(1) 32-38.

Udaya Bhaskar T V S, Ravichandran M and Devender R 2007 An operational objective analysis system at INCOIS for generation of Argo value added products, Report No.: INCOIS-MOG-ARGO-TR-04-2007.

Verron J 1992 Nudging satellite altimeter data into quasigeostrophic ocean models; J. Geophys. Res. 97 74797491.

Verron J, Gourdeau L, Pham D T, Murtugudde R and Busalacchi A 1999 An extended Kalman filter to assimilate satellite altimeter data into a non-linear numerical model of the tropical Pacific: Method and validation; J. Geophys. Res. 104 5441-5458.

Vorosmarty C J, Fekete B and Tucker B A 1998 River discharge database, version 1.1 (RivDIS v1.0 supplement) [available online at http://www.rivdis.sr.unh.edu].

Weaver A T, Vialard J and Anderson D L T 2003 Three- and four-dimensional variational assimilation with a general circulation model of the tropical Pacific Ocean. Part I: Formulation, internal diagnostics, and consistency checks; Mon. Weather Rev. 131 1360-1378. 